\title{
Special Section on Cyber-Physical \& Human Systems (CPHS)
}

Introduction: As a consequence of the computer and internet revolution, Cyber-Physical Systems (CPS) have facilitated huge breakthroughs in recent decades in the development of new technologies to improve citizens' lives, with impacts seen in many different sectors of society including healthcare, urban planning and mobility, and energy management.

Another aspect of CPS is the increasingly close alignment with Humans, which has given birth to the new field of investigation on Cyber Physical and Human Systems (CPHS). Indeed, as systems grow in complexity, their operation or cooperation with Humans requires multidisciplinary collaborative research - scientists involved with research in human sciences and control and ICT researchers have to collaboratively investigate common open problems that cannot be tackled by experts in one discipline alone.

In terms of whole system design, this includes all the different steps in system conception and use: modeling, information acquisition and processing, control design, implementation, operation, and maintenance. For these tasks and others, the human element needs to be more formally and rigorously understood, analyzed, and modeled. Moving forward, key questions involving ethics and human sciences become pertinent: where are the frontiers of technology/control and human action? Where is only the machine involved and which cases represent the domain for human concern only? The power of the emerging disciplines of CPS and CPHS suggest that it is very important to anticipate and identify possible negative effects so that appropriate investigation and subsequent actions can preempt problems as discussed in [1-3].

Nonetheless, not all the possibilities and potential benefits from the evolution of CPS have yet been identified. This calls for a study of those additional benefits which could be achieved and the corresponding control and other open problems that would need to be addressed to achieve them. For example, robotic surgery can still make advances provided that some open problems in shared control make the necessary significant steps, as highlighted in the H-CPS-I workshop, in Paris, in 2014 [1]. For studying answers to such questions, it is certainly necessary to widen exchanges between different scientific communities involving experts in cognitive sciences, ergonomics, social and economic sciences, computer, robotics, control sciences amongst others. The importance of investigation in the CPHS field has also been recently highlighted in [3].

The discussion above affords evidence of the reasons for the high engagement and efforts since 2013 of a very active group of international researchers to create and launch a series of conferences on this topic: the Workshop H-CPS-I 2014 (on Human Cyber-Physical-System Interaction : Control for Human Welfare, in Paris, 2014, that has been co-sponsored by IFAC and by the IEEE CSS Outreach Fund; and also by the following institutions and organizations: IFSTTAR, HYCON2, CNRS, GDR MACS, SEE, EECI, iCODE and VeDeCom) led by Mariana Netto, Sarah Spurgeon, Francoise Lamnabhi-Lagarrigue and Tariq Samad (respectively as co-chairs, NOC chair and vice chair) [1]; the 1st IFAC Conference CPHS 2016 (on Cyber-Physical and Human Systems, in Florianopolis, Brazil, 2016, co-sponsored by the IEEE CSS Outreach Fund, the National Science Foundation, IFSTTAR, CNRS, EECI, UFSC, iCODE and the GDR MACS), led by Mariana Netto as general chair, Francoise Lamnabhi-Lagarrigue as the steering committee advisor, Sarah Spurgeon as program chair and Ubirajara F. Moreno as NOC chair [2]. Finally, the upcoming 2nd CPHS 2018, in Miami, on December 2018, led by Anuradha Annaswamy and Dawn Tilbury as (co) general chairs and Sandra Hirche as the program chair [4]. In addition, many other key people have been highly supportive of the events such as for example the past IFAC president Janan Zaytoon (2014-2017), Wilfrid Perruquetti, Berenice Mettler, Ruzena Bajcsy, Ronald Hess, Alexander Efremov and the IEEE CSS Outreach chairs Bernard Rivera and Gary Balas. These events facilitated the development of open questions in the CPHS field. They also allowed a structure for CPHS systems to be established. This is necessary because of the large scope of the field (please see Table 1).

Outline of the section: For the reasons discussed above, the creation of the CPHS conference has been dedicated to stimulating work in the field of control design for the welfare of human beings, facilitating interaction between disciplines as required to better address CPHS challenges. This special issue is dedicated to reporting early contributions. It contains eight papers that address three stages of system design as described above: (Human) modeling (papers 1-5), making use of distinct modeling approaches, information 
acquisition and processing (paper 6) and control design (papers 7-8). These papers are extended versions of work presented in the 1st CPHS 2016 in Brazil.

This section also aims to highlight the importance of combining efforts from different ICT communities and human sciences communities in addressing the whole control problem. One example may be found in the domain of transport and concerns the deployment of road automation: if precise control problems need to be addressed, key challenges are also in how to achieve a highly reliable environmental perception system, which is required as an input for control and is an issue that is addressed in paper 6; Road automation requires contributions from psychologists and ergonomists concerning the transitions between the human and the automat, which is indeed a very difficult problem, since automation can potentially generate distraction and give rise to the out-of-the-loop performance problem - a known challenge in automation. Some insights to this problem are given in paper 4 from a neuroergonomics viewpoint. Finally, the deployment of semi-automated systems call also for human scientists to study the gaps between expected human behaviors and their effective behaviors and the human reliability that is related to the system's resilience (paper 5).

On Human modeling, paper 1 reviews current advances and the authors' own contributions in the analysis and modeling of human spatial planning, perception and learning. The research reviewed in paper 2 on human control activity modeling, born mostly from the aviation domain, has found recently its importance in other domains as in the design of shared steering control for ground vehicles, as highlighted in paper 3. Control sharing in human-robot team interaction has great importance in the robotics domain, as described in paper 6. Indeed, the control applications described in paper 6, and in paper 7, on Functional Electrical Stimulation to support human mobility following complete or partial paralysis, illustrate the importance of CPHS in control. A description of the contributions follows:

1) Modeling and Analysis of Human Perception and Learning in Skilled Spatial Tasks based on AgentEnvironment Dynamics, by Berenice Mettler, Abhishek Verma and Andrew Feit, reviews current advances and the authors' own contributions in the analysis and modeling of human spatial planning, perception and learning based on the dynamics of agent-environment interactions.

2) Review of control models for human pilot behavior, by Shuting $\mathrm{Xu}$, Wenqian Tan, Alexander V. Efremov, L. G. Sun, Xiangju Qu, presents a review of control models for human pilot behavior, with the purpose of analyzing the characteristics of the pilot-aircraft system. This is a fundamental step in providing valuable guidance in flight control system design.

3) Modeling the Human Control of Steering for the Design of Advanced Driver Assistance Systems, by Franck Mars and Philippe Chevrel, addresses a careful modeling approach and also includes control design. The authors review current advances and the authors' own contributions to an interdisciplinary approach for the design of a cybernetic model of the human being. The model is used for the design of haptic shared control automaton, showing how model prediction can help to improve steering performance.

4) A neuroergonomic approach of the out-of-the-loop performance problem, by Bruno Berberian, Bertille Somon, Aisha Sahai and Jonas Gouraud, studies the "out-of-the-loop" (OOTL) performance problem, one of the main challenges related to automation, through a neuroergonomic human modeling approach.

5) Towards increased systems resilience: new challenges based on dissonance control for human reliability in Cyber-Physical\&Human Systems, by Frederic Vanderhaegen, details several new challenges for analyzing and controlling human reliability of a cyber-physical and human system to increase the system's resilience.

6) Perception, information processing and modeling: critical stages for autonomous driving applications, by Dominique Gruyer, Valentin Magnier, Karima Hamdi, Laurène Claussmann, Olivier Orfila, and Andry Rakotonirainy, reviews reliability and robustness issues relating to sensor processing and perception, a necessary condition for ensuring a high level of safety in the deployment of autonomous driving applications. 
7) Control sharing in human-robot team interaction: a survey, by Selma Music and Sandra Hirche surveys advances in human-robot team interaction, paying special attention to the problem of combining human and robot team decision making and task execution capabilities, i.e. control sharing.

8) Sensing Motion and Muscle Contraction for Feedback Control of Functional Electrical Stimulation, by Thomas Schauer reviews the use of electrical nerve stimulation to artificially generate functional muscle contractions and support cycling, walking, reaching and swallowing following complete or partial paralysis due to stroke or spinal cord injury.

Mariana Netto, IFSTTAR, France, and Sarah Spurgeon, UCL, UK.

\begin{tabular}{|c|c|c|c|c|}
\hline \multicolumn{5}{|c|}{ MODELLING } \\
\hline \multicolumn{5}{|c|}{$\begin{array}{l}\text { e.g. models of the human being cognitive activity level, cybernetic driver models, models of the motion of groups of human } \\
\text { beings (work on flocky logic from N. Leonard and S. Marshall), models of the creativity processes. }\end{array}$} \\
\hline \multicolumn{5}{|c|}{ DECISION and CONTROL } \\
\hline & HUMAN-CENTERED CONTROL & \multicolumn{3}{|c|}{ MACHINE-CENTERED CONTROL } \\
\hline & Human-machine symbiosis & $\begin{array}{l}\text { Humans as } \\
\text { operators of } \\
\text { complex eng. } \\
\text { systems }\end{array}$ & $\begin{array}{l}\text { Humans as agents in } \\
\text { multi-agent teams }\end{array}$ & $\begin{array}{l}\text { Humans as } \\
\text { elements in } \\
\text { controlled } \\
\text { systems }\end{array}$ \\
\hline $\begin{array}{l}\text { MEDICAL } \\
\text { APPLICATIONS }\end{array}$ & $\begin{array}{l}\text { Individualized neuroprosthetics: } \\
\text { overlaps with the modelling and } \\
\text { control domains, here specifically } \\
\text { tailoring the therapy to the specific } \\
\text { patient }\end{array}$ & $\begin{array}{l}\text { Robots for } \\
\text { cancer surgery }\end{array}$ & & \\
\hline $\begin{array}{l}\text { TRANSPORTATION } \\
\text { AND INDUSTRY }\end{array}$ & & $\begin{array}{l}\text { Aircraft pilots, } \\
\text { train driver, car } \\
\text { drivers, process } \\
\text { plant operators }\end{array}$ & $\begin{array}{l}\text { Coordination of } \\
\text { UAVs and piloted } \\
\text { aircraft in commercial } \\
\text { airspace; } \\
\text { Traffic control }\end{array}$ & \\
\hline SMART GRIDS & & & & $\begin{array}{l}\text { Comfort control } \\
\text { in homes \& } \\
\text { buildings }\end{array}$ \\
\hline \multicolumn{5}{|c|}{ PHILOSOPHICAL AND ETHICAL ISSUES: Humans and technology, the limits of technology, etc. } \\
\hline \multicolumn{5}{|c|}{$\begin{array}{l}\text { 1) What are the limits on what only technology can do? What can (should) only a human being do? 2) At what point is the } \\
\text { computer taking over key experiences of being human? How to provide maximum benefits from technology avoiding possible } \\
\text { negative effects? }\end{array}$} \\
\hline
\end{tabular}

Table 1: The three stages (modeling, decision and control) for a system design, with the four classes of interaction between the Human and the CPS, as defined in H-CPS-I 2014, in Paris.

\section{References:}

[1] H-CPS-I 2014, Website of the IFAC IEEE CSS Workshop Human Cyber Physical System Interaction: Control for Human Welfare https://h-cps-i.sciencesconf.org/.

[2] Proceedings of CPHS 2016 - $1^{\text {st }}$ IFAC Conference on Cyber-Physical \& Human-Systems, IFAC-PapersOnLine, Volume 49, Issue 32, Pages 1-252 (2016), Edited by Leandro Buss Becker.

http://www.sciencedirect.com/science/journal/24058963/49?sdc=1

[3] F. Lamnabhi-Lagarrigue, A. Annaswamy, S. Engell, A. Isaksson, P. Khargonekar, R. Murray, H. Nijmeijer, T. Samad, D. Tilbury, P. Van den Hof, Systems \& Control for the Future of Humanity, Research agenda: current and future roles, impact and grand challenges, Annual Reviews in Control, 2017.

[4] CPHS 2018, Website of the $2^{\text {nd }}$ IFAC Conference on Cyber-Physical \& Human-Systems, http://www.cphs2018.org/. 